of histological appearances in both pre- and postnatal life is first described, followed by the various methods available for the study of pulmonary vascular morphology. The discussion then ranges over pulmonary hypertension, pulmonary venous hypertension, pulmonary embolism, pulmonary vascular changes in intrinsic disease of the lung, and concludes with sections on congenital anomalies of the major pulmonary vessels, and neoplasms and hamartomas of the pulmonary vasculature.

This book should certainly be read by all pathologists concerned with cardiopulmonary disease, and it should also become a standard work of reference in all cardiac and respiratory units.

\section{Angiotensin Systems and Experimental Renal Diseases}

Proceedings of the Fourteenth Annual Conference on the Kidney sponsored by National Kidney Disease Foundation. Edited by JACK MetCofF, M.D. Pp. xvii +268 , illustrated. London: J. A. Churchill. 1963. 55s.

This is the report of the proceedings of the 1962 conference sponsored by the National Kidney Disease Foundation. The number of participants had been increased from the previous number of forty or fifty to almost eighty. It was hoped that this would still allow informal presentation and discussion of papers.

The papers are in two main groups. The first is concerned with Angiotensin and its relationships with the juxtaglomerular cells of the kidney, experimental hypertension, the cardiovascular system and aldosterone and other adrenal steroids. The papers in the second group describe experimental work on pyelonephritis and the nephrotic syndrome, also 'selective reactions of glomerulus and tubules' (including electron microscope observations on human fœtal kidneys).

This book describes work of great interest to nephrologists and those working in the field of experimental hypertension. There is wide variation in the quality of the papers. Those on the juxtaglomerular cells by Phyllis Hartroft and Louis Tobian are very good, as might be expected, for they have made major contributions to the study of these fascinating and puzzling structures. Two papers on experimental pyelonephritis in rats suggest that antigen may persist in renal tissue, in some areas of chronic inflammation, in the absence of viable bacteria; this may in time be shown to be relevant to the progress of chronic pyelonephritis in man.

One of the papers on Aminonucleoside 'nephrosis' induced in Formosan monkeys, contributes no observation or conclusion of value and appears out of place in this book. Another, 'Electron Microscopic Observation in Antigen-Antibody Reactions in the Glomerulus', hints at work of great complexity and interest but produces conclusions which would not appear to be justified by the evidence presented.

It is perhaps a pity that the proceedings of conferences and symposia, such as this, are not edited mare severely. There is no great merit in the reproduction of papers and discussions almost unaltered. The reader who is not familiar with the particular field of work or with the status of participants needs more critical guidance. It would be a help if some of the more senior participants were to add their own final assessments of the papers and discussions, written some time after the conference, to each section.
The Growth and Development of the Prematurely Born Infant

C. M. Drillen. Pp. xv + 316. Edinburgh and

London: E. \& S. Livingstone. 1963. 50s.

This book is the outcome of a long and painstaking study of a subject of increasing importance to pædiatrics, and all who know of Dr. Drillen's work in Edinburgh, and have heard her lecturing on this topic, have awaited its appearance eagerly. They will not be disappointed.

The Edinburgh study was a longitudinal survey of all surviving prematures and twins born to a group of 1,000 mothers delivered in two hospitals during 1953-5, plus a control group of mature babies obtained by selecting the next mature birth after every alternate premature birth. In all, 370 singletons and 225 twins were recruited. After an initial hospital interview, at which all relevant personal obstetrical and sociological information was recorded, the babies were seen at six months, and thereafter regularly up to the age of five years. After this, information was obtained for several more years from the school authorities. Assessments were made of physical and mental development, health and sickness, and patterns of maternal care, and these subjects are considered in separate chapters, each liberally supplied with tables and charts, a useful summary, and a large number of references. A separate chapter is devoted to babies of very low birth weight.

Pædiatricians will not generally be surprised at the main conclusions of the survey, namely that premature delivery is likely, though by no means certain, to impose physical and intellectual disadvantages, though they may not entirely realise how these disadvantages may be modified in both directions by environmental factors, such as social class and the standard of maternal care. They will also find that their worst fears about the prognosis of very low birth-weight babies are unfortunately confirmed. As example is given by intelligence tests of 66 school-age children, who had been $3 \mathrm{lb}$. or less at birth; only six scored 100 per cent or over, and one third were ineducable.

This is far from being the largest such study of premature babies, but it does not suffer in comparison with others. Its modest size in fact give it the advantage that the author was able to keep personal checks on cases and data in a way not possible for very large surveys. The imprint of her personality was also shown by the small percentage of losses from the original sample.

The book is pleasingly produced and presented, though rather high in price. This may be a reflection of the large number of tables, some of considerable complexity, and prompts the heretical speculation whether they are all really necessary, or at least whether graphical display methods could not have been used more. However, this is essentially a reference work, and as such, can be thoroughly recommended.

Advances in Enzyme Regulation, Volume 1

Edited by George Weber. Pp. xiv +420 ,

illustrated. Oxford, London, New York and Paris: Pergamon. 1963. £5.

The emergence of increasing numbers of review volumes is one aspect of the progress of science, although viewed with mixed feelings by scientists. This usually stems from a growing frustration in attempts to keep up with the ever increasing literature. Specialties fragment into sub-specialties, which 